\title{
Educación poética en el aula. Un modelo a partir de la creatividad de Mariluz Escribano'
} \author{
of Mariluz Escribano \\ AURORA MARTÍNEZ EZQUERRO \\ Universidad de La Rioja \\ España \\ aurora.martinez@unirioja.es
}

Poetic Education in the classroom.A model from the creativity

(Recibido: I9-I2-2O2O; aceptado: O8-II-2O2I)

Resumen. La educación poética en las aulas de Educación Secundaria precisa una metodología que fomente las competencias curriculares. Diversos estudios han realizado aportaciones para la mejora de este enfoque, si bien las investigaciones más productivas se han centrado en Educación Primaria. Se acusa, por tanto, la necesidad de aportar un método adecuado al nivel y diversidad del alumnado de enseñanzas medias. Teniendo en cuenta las necesidades expuestas, en el presente artículo se analiza, en primer lugar, el enfoque que la legislación ofrece para abordar la educación poética; posteriormente y con método comparativo, se cotejan los instrumentos curriculares de la práctica poética recogidos en manuales de Secundaria. A partir de los resultados obtenidos, se valora y muestra la utilidad de aplicar una nueva metodología colaborativa de "reflexión poética activa" que mejora la práctica habitual del análisis textual, y para ello se toma como modelo la creación poética de la escritora granadina Mariluz Escribano, con quien se rescata parte del canon literario femenino soterrado en los manuales al uso. El método aplicado -caracterizado por su flexibilidad- constituye un instrumento curricular que fomenta, entre otras competencias, la capacidad interpretativa inherente al análisis poético en un espacio de reflexión compartida.

Palabras clave: Educación poética; metodología; Educación Secundaria; comentario de texto; Mariluz Escribano.

\footnotetext{
${ }^{\text {I }}$ Para citar este artículo: Martínez Ezquerro, Aurora (2022). Educación poética en el aula. Un modelo a partir de la creatividad de Mariluz Escribano. Alabe 25 . [www.revistaalabe.com] 
Abstract. Poetic education in Secondary Education classes requires a method that develops the competencies of the curriculum. Various studies have conducted research to improve this approach, but the most appropriate research is from Primary Education. It is necessary to provide an appropriate method to the educational level and to the diversity of secondary school students. With these needs in mind, this article analyzes, firstly, the approach that the legislation offers to study poetic education. Later, and with a comparative method, the curricular instruments of the poetic practice of the Secondary manuals are compared. With the results obtained, the usefulness of applying a new collaboration methodology of "active poetic reflection" that improves on the usual practice of textual analysis, is shown and assessed.To these ends, the poetic creation of the writer from Granada Mariluz Escribano is taken as a model, which rescues part of the feminine literary canon that is hidden in the user manuals. The applied method -characterized by its flexibility- constitutes a curricular instrument that develops, among other competences, the ability to interpret, inherent to poetic analysis in a space of shared reflection.

Keywords: Poetic education; methodology; secondary school; text commentary; Mariluz Escribano. 


\section{"Los escritores miran a veces con los ojos de la memoria, porque les gusta viajar por el tiempo, abrir la caja de los secretos [...]”. Lecciones de poesía para niños inquietos, L. García Montero, 1999 (pág. 7o)}

\section{Sobre la educación poética en el aula ${ }^{2}$}

La poesía en el aula desempeña un papel educativo que fomenta diversas competencias, como son la comunicativa, literaria, artística, estética o personal, entre otras (López Valero y Encabo, 2OI3). El género poético, después del teatro, es uno de los olvidados en las aulas (Sánchez García, 20I8) y precisa una adecuada planificación docente. Para contrarrestar estas carencias, algunos estudiosos se han acercado a la didáctica de la literatura y han aportado interesantes métodos dinamizadores (Muñoz, I983; Ortega, I986; García Rivera, I995; Gómez Martín, 2002; Martínez Ezquerro, Pérez Pastor y Beltrán Falces, 2008; López Valero y Jerez, 20IO; Campos F.-Fígares, 20I6, entre otros), si bien predominan trabajos vinculados principalmente a la Educación Primaria y desde la perspectiva de la creación. En el nivel educativo de Secundaria se recogen menos investigaciones, que resultan muy útiles no solo porque ponen de relieve su valor competencial en el desarrollo de las clases, sino también porque ofrecen técnicas que replantean métodos diferentes a los tradicionales (Rincón y Sánchez-Enciso, I986; Moreno, I989; Martínez Ezquerro, 2002; Martínez Ezquerro y Quiles Cabrera, 20r9; Quiles Cabrera, Martínez Ezquerro y Palmer, 20r9; Campos F.-Fígares y Quiles Cabrera, 20r9, etc.).

Más de dos décadas como docente de Educación Secundaria aportan experiencia para conocer y reconocer los planteamientos en el desarrollo habitual de la planificación docente del profesorado. La mayoría se aferra a los programas y, en consecuencia, a los libros de texto; pero también deben ser mencionados los docentes que no se conforman con un resultado nulo, esto es, con alumnado que no entiende ni aprende, y que reaccionan ante tal situación aportando una perspectiva renovada de la enseñanza poética que es una respuesta (Pardo Caicedo y Munita, 2O2I) a la falta de objetivos alcanzados. De forma general, estos educadores trascienden el espacio físico del aula y la convierten en lugar de creación y reflexión compartida, a modo de taller en el que el profesor es un mediador;

\footnotetext{
${ }^{2}$ El presente artículo se enmarca en el Proyecto de Investigación “Las olvidadas. Proyecto de recuperación digital de la poesía femenina andaluza aplicada al aula (19OO-2OOO)". Ref. B-HUM-44O-UGRi8 (2O2O-2O2I).
} 
asimismo, amplían el elenco de lecturas y dan protagonismo a eventos poéticos vinculados a la poesía (nacimiento de un poeta, día del libro, fechas señaladas, etc.) en los que el discente muestra su trabajo (recitación, creación, etc.). En suma, el punto de partida es la consideración de este género como una útil herramienta que redivive momentos vitales y contribuye a transmitir pensamientos, vivencias y sentimientos mediante el uso de un lenguaje especialmente elaborado para tales fines. Esta comunicación literaria permite compartir valores que responden al amor, amistad, felicidad, etc., que se concretan en estados afectivos comunes a todas las personas.

A estas valoraciones añadimos que los adolescentes se hallan en un momento crucial de su desarrollo cognitivo y psicosocial; la poesía, en este sentido, es un género muy adecuado en dicho estadio de evolución personal puesto que permite estimular la capacidad de interiorizar, comunicar y desarrollar la creatividad como manifestación de sentimientos. Asimismo, fomenta las competencias comunicativas orales y escritas ya que la atención pedagógica se dirige en la doble dimensión del hecho poético (como palabra escrita y oral).

\section{Principios didácticos para la educación poética: "Metodología de reflexión poé- tica activa"}

Partimos de la premisa de que en el ámbito educativo la poesía debe ser no solo texto leído sino "texto recreado y práctica creativa en un espacio compartido". El alumno es el receptor de poesía y, por tanto, debe aprehenderla, sentirla, crearla y recrearla a partir de adecuadas intervenciones metodológicas que lo pongan en contacto con unas perspectivas más próximas a sus vivencias o conocimientos. En este sentido, las dimensiones procedimental y actitudinal resultan idóneas para abordar el conocimiento, la práctica y la valoración del género.

Consideramos que, para desarrollar la educación poética, el tradicional tratamiento que se le otorga a la poesía no debe aprenderse exclusivamente a partir de movimientos literarios en los que se hallan enmarcados los autores, esto es, aplicando el modelo historicista (Martínez Ezquerro, 2OI7). Con el fin de superar estas intervenciones generalizadas en las aulas, proponemos la "metodología de reflexión poética activa”, que parte de que la lectura poética (individual y colectiva) se vincula a la emoción y la sensibilidad (como experiencia), y se expresa con un lenguaje plurisignificativo que recurre al ornatus (Spang, I997, 2005). He aquí la importancia de guiar al alumno (en su aprendizaje individual y colectivo) para educar la sensibilidad literaria y compartir esta experiencia emotiva, e incluso crearla o recrearla. El papel del profesor como mediador estimula el gusto poético e incentiva la reflexión conjunta (Martínez Ezquerro, 20I6) en el espacio colaborativo inherente a la enseñanza. El docente debe valorar, asimismo, la diversidad de su alumnado con el fin de conocer sus motivaciones e intereses, y esto le permitirá ampliar el corpus lector; asimismo, en las prácticas ofrecerá una progresión hacia la com- 
plejidad de la experiencia lectora y creadora. Las intervenciones didácticas se enriquecen a la luz de la reflexión poética individual y compartida en un espacio dinámico en el que el trabajo procedimental se desarrolla, por ejemplo, en un taller poético (Rodari, I983; Sánchez-Enciso y Rincón, 1985; Ortega, rg86; Rincón y Sánchez-Enciso, I986; Lomas, I999; Barrientos, I999; Moreno, 1999; Sánchez-Enciso, 2004, etc.).

La "metodología de reflexión poética activa" otorga protagonismo al desarrollo competencial en su triple dimensión, esto es, conceptual (no se anteponen como objetivos prioritarios los conocimientos), procedimental (aprendizaje a partir de las variadas intervenciones) y actitudinal (trabajo colaborativo, eliminación de prejuicios, igualdad, tolerancia y respeto, favorecimiento de actitudes positivas, pensamiento crítico, etc.) porque "Educar en valores constituye uno de los objetivos básicos para la íntegra formación del alumnado y debe abordarse transversalmente en las diversas etapas educativas" (Martínez Ezquerro, 20I7: 247). Mostramos los elementos que intervienen en el método didáctico expuesto:

\section{ESPACIO COLABORATIVO}

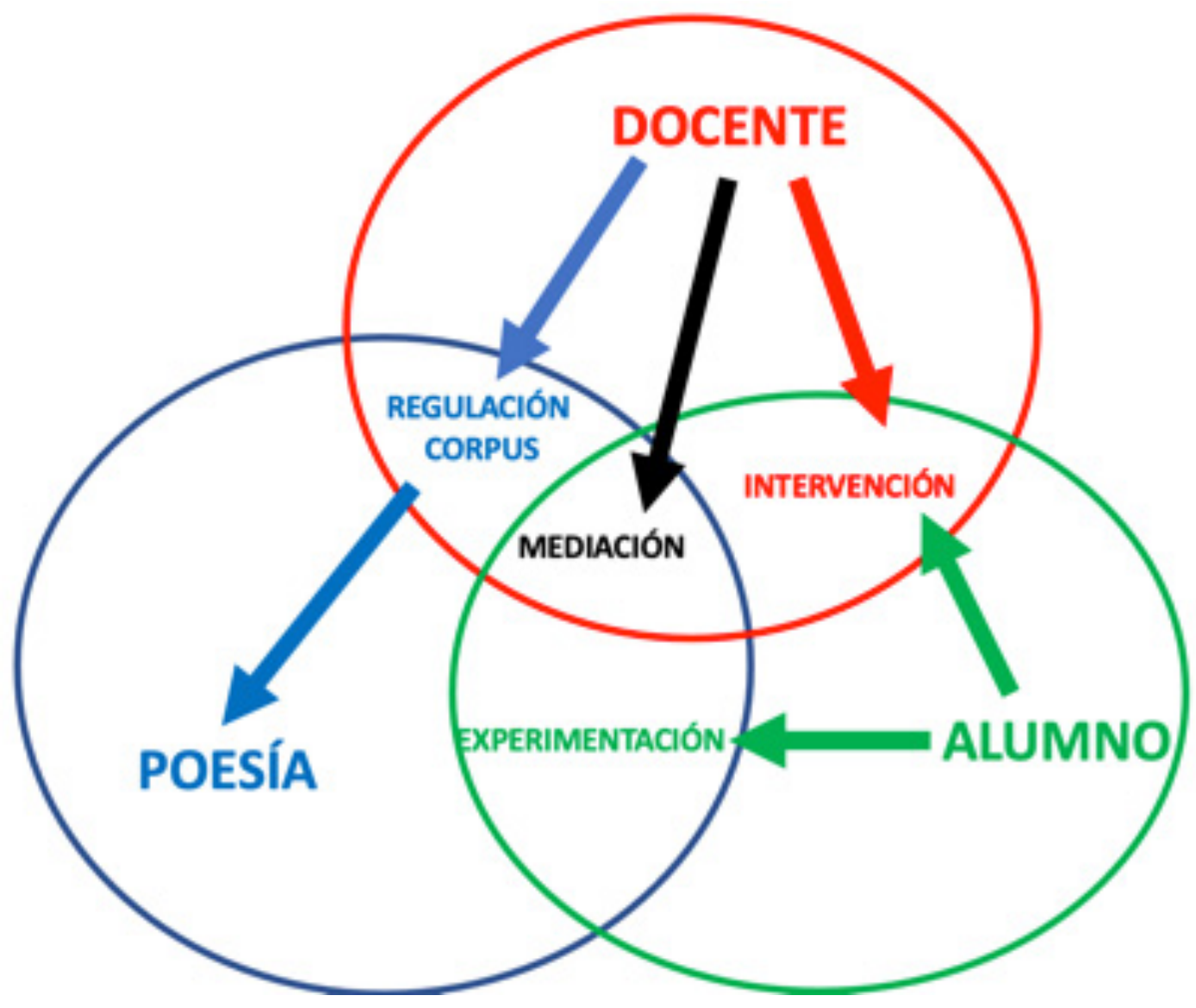

Fig.r. Metodología de reflexión poética activa 
El espacio común que conforma la mediación permite que el docente trabaje a partir de las premisas indicadas; esto es, valorando la diversidad del alumno, y, en consecuencia, regulando el corpus, sin olvidar el cambio del paradigma desarrollado en la posmodernidad (Martos y Campos, 2OI2: 2-3). Como sabemos, las estrategias para practicar la poesía son variadas y algunas de ellas se basan en ejercicios de Rodari (I983), en las posibilidades que ofrece la poesía recitada o musicalizada (medio muy adecuado en las aulas de Secundaria puesto que aproxima al género desde un arte que es instrumento comunicativo propio de la adolescencia) o en las actividades oulipianas (quimeras, lipogramas, topogramas...), a modo de ejemplo. Asimismo, destacamos que la conexión de este género con otras artes desarrolla un adecuado trabajo interdiscursivo, que según García Rivera (1985):

[...] Pelegrín ha estudiado, de forma paralela, procedimientos de interconexión de lo poético con lo plástico, la expresión corporal, la dramatización, etc. [...] En el fondo es una cuestión de facilitación psicológica. Si, como sostiene el psicólogo norteamericano Paivio, la mente procesa la información sirviéndose de una doble codificación icónica y verbal (teoría de la "doble codificación”), podemos reforzar la comprensión de imágenes verbales activando a la vez imágenes icónicas. [...] Este mismo principio de ayuda de la memoria icónica a la memoria verbal es lo que hemos aplicado en los Ideogramas. De hecho, cuando un alumno lee expresiones como "rosas rojas de tus rosales" de A. Machado, inevitablemente se forma o evoca una imagen mental de ello, por lo que todo lo que sea activar esa imagen con estímulos visuales, sonoros o del tipo que sean reforzará la comprensión. (García Rivera, 1985: 220)

La práctica de la recitación y la consiguiente reflexión tampoco deben desatenderse y constituyen, asimismo, actividades que fomentan competencias en el alumnado, algunas de las cuales responden a la coordinación de lenguaje verbal y gestual; la valoración de la importancia de expresar sentimientos, conflictos o alegrías a través de la representación teatral; la alfabetización poética que permite, asimismo, ser lector activo y crítico; el desarrollo de la comprensión lectora; el fomento del hábito lector y del gusto por la lectura; la ampliación lingüístico-retórica; la estimulación de la imaginación y de la creatividad, etc.

El acercamiento al texto poético como tal es necesario desde el punto de vista estilístico y se debe tener en cuenta la fascinación que los alumnos sienten hacia la experimentación lingüística que ofrece, por ejemplo, el arte vanguardista; en este sentido, compartimos la reflexión de Quiles, Palmer y Rosal (2015: 52-53), quienes afirman que "el humor, los juegos de palabras, las alusiones metafóricas, las hipérboles, los símiles, las personificaciones [...] son fenómenos emparentados con la infancia desde sus primeras palabras. [...] su experimentación con el lenguaje en sus primeros años de vida adquiere una gran vinculación con los fundamentos de movimientos como el Modernismo, el Expresionismo o el Postismo". Se hace necesario, en este contexto, aplicar con perspectiva 
didáctica las posibilidades que ofrece la poesía, según hemos indicado, sin desestimar el auge que las nuevas tecnologías desarrollan en torno a las redes sociales como medios de promoción y divulgación de una nueva literatura construida por y para jóvenes (Sánchez García y Aparicio Durán, 2O2O; Quiles Cabrera, 2O2O; Leal Rivas, 2O2O, etc.).

\section{Legislación educativa y educación poética}

Las orientaciones curriculares de la educación poética se incardinan en perspectivas artístico-estéticas, pedagógicas y sociológico-culturales. Ya hemos señalado que la educación poética parte de la experimentación en un espacio individual/compartido en el que la diversidad de los aprendientes revive, comprende, valora, crea, recrea, reflexiona y comparte emociones (sentimientos, vivencias...), que se experimentan a partir del conocimiento procedimental de un corpus poético. Estos objetivos se hallan en conexión con el valor que la legislación educativa otorga a la formación de personas con capacidad crítica, a la diversidad o a la adecuación a nuevas realidades personales y sociales, y así en la LEY ORGÁNICA 8/2OI3, de 9 de diciembre, para la mejora de la calidad educativa (BOE, IO de diciembre de 2OI3), leemos en su Preámbulo (secciones I y IV):

[...] El aprendizaje en la escuela debe ir dirigido a formar personas autónomas, críticas, con pensamiento propio [y] serán objeto de una atención, en la búsqueda de desarrollo del talento [...]. El reconocimiento de esta diversidad [...] es el primer paso hacia el desarrollo de una estructura educativa que contemple diferentes trayectorias. [...] La educación es la clave de esta transformación [así que] es necesario adquirir desde edades tempranas competencias transversales, como el pensamiento crítico, la gestión de la diversidad, la creatividad o la capacidad de comunicar, y actitudes clave como la confianza individual, el entusiasmo, la constancia y la aceptación del cambio. [...] Necesitamos propiciar las condiciones que permitan el oportuno cambio metodológico, de forma que el alumnado sea un elemento activo en el proceso de aprendizaje.

Teniendo en cuenta que la presente investigación abarca el último curso de Educación Secundaria, esto es, segundo de Bachillerato, destacamos los aspectos vinculados a la educación literaria recogidos en el Real Decreto IIO5/20I4, de 26 de diciembre, por el que se establece el currículo básico de la Educación Secundaria Obligatoria y del Bachillerato (BOE, 3 de enero de 20I5). Así en el Capítulo III, Bachillerato, Artículo I4. Principios generales, se exponen los objetivos que desarrollan capacidades relacionados con la educación literaria. Seleccionamos los siguientes:

b) Consolidar una madurez personal y social que les permita actuar de forma responsable y autónoma y desarrollar su espíritu crítico [...].

d) Afianzar los hábitos de lectura, estudio [...] como medio de desarrollo personal. 
e) Dominar, tanto en su expresión oral como escrita, la lengua castellana [...].

f) Expresarse con fluidez y corrección [...].

g) Utilizar con solvencia y responsabilidad las tecnologías de la información y la comunicación.

h) Conocer y valorar críticamente las realidades del mundo contemporáneo [...].

k) Afianzar el espíritu emprendedor con actitudes de creatividad, flexibilidad, iniciativa, trabajo en equipo, confianza en uno mismo y sentido crítico.

1) Desarrollar la sensibilidad artística y literaria, así como el criterio estético, como fuentes de formación y enriquecimiento cultural.

Comprobamos que las bases generales de Bachillerato se vinculan a los objetivos de la educación poética (con las correspondientes relaciones procedimentales y actitudinales). En este sentido y continuando con el cotejo legislativo, en el Anexo I del documento que venimos analizando, la materia de Lengua Castellana y Literatura recoge unos principios para todos sus niveles, y en el desarrollo del bloque que corresponde a Educación Literaria indica que conforma "un marco conceptual que alterna la lectura, comprensión e interpretación de obras literarias cercanas a sus gustos personales y a su madurez cognitiva, con la de textos literarios y obras completas que aportan el conocimiento básico sobre algunas de las aportaciones más representativas de nuestra literatura. [...]", sin olvidar la relación entre el contexto sociocultural y la obra literaria; se indica, asimismo, que "es importante favorecer la lectura libre de obras de la literatura española y universal de todos los tiempos y de la literatura juvenil”, porque el objetivo es ampliar los corpus y adaptarlos a la diversidad del alumnado y del contexto actual (nuevos poetas que no se incluyen en el canon). La legislación educativa incide en la importancia de conseguir lectores que continúen leyendo y "que se sigan formando a través de su libre actividad lectora a lo largo de toda su trayectoria vital: personas críticas capaces de interpretar los significados implícitos de los textos a través de una lectura analítica y comparada de distintos fragmentos u obras [...] aprendiendo así a integrar las opiniones propias y las ajenas".

En suma, la materia Lengua Castellana y Literatura plantea el objetivo de "crear ciudadanos conscientes e interesados en el desarrollo y la mejora de su competencia comunicativa, capaces de interactuar satisfactoriamente en todos los ámbitos que forman y van a formar parte de su vida. Esto exige una reflexión sobre los mecanismos de usos orales y escritos de su propia lengua, y la capacidad de interpretar y valorar el mundo y de formar sus propias opiniones a través de la lectura crítica de las obras literarias más importantes de todos los tiempos". Como sabemos, el enfoque comunicativo centrado en el uso funcional de la lengua se articula alrededor de las destrezas discursivas que la lectura fomenta (Leal Rivas, 202O). El educador debe desarrollar la comprensión y la expresión oral (y escrita) junto con la educación literaria, de forma que quedan ligadas las destrezas desde sus perspectivas procedimental y actitudinal. 
Teniendo en cuenta que uno de los objetivos de la presente investigación es analizar los modelos de comentario poético que los manuales de segundo de Bachillerato ofrecen, mostramos los contenidos de Educación Literaria (bloque 4) recogidos en el anterior documento legislativo: Estudio cronológico de las obras más representativas de la literatura española del siglo XX hasta nuestros días; Análisis de fragmentos u obras significativas del siglo XX hasta nuestros días; Interpretación crítica de fragmentos u obras significativas del siglo XX hasta nuestros días; y Planificación y elaboración de trabajos académicos escritos o presentaciones sobre temas, obras o autores de la literatura del siglo XX hasta nuestros días. En relación con los mismos, mostramos los criterios de evaluación:

I. Conocer los aspectos temáticos y formales de los principales movimientos literarios del siglo XX hasta nuestros días, así como los autores y obras más significativos.

2. Leer y analizar textos literarios representativos de la historia de la literatura del siglo XX hasta nuestros días, identificando las características temáticas y formales y relacionándolas con el contexto, el movimiento, el género al que pertenece y la obra del autor y constatando la evolución histórica de temas y formas.

3. Interpretar de manera crítica fragmentos u obras de la literatura del siglo XX hasta nuestros días, reconociendo las ideas que manifiestan la relación de la obra con su contexto histórico, artístico y cultural.

4. Desarrollar por escrito un tema de la historia de la literatura del siglo XX hasta nuestros días, exponiendo las ideas con rigor, claridad y coherencia y aportando una visión personal.

5. Elaborar un trabajo de carácter académico en soporte papel o digital sobre un tema del currículo de Literatura consultando fuentes diversas, adoptando un punto de vista crítico y personal y utilizando las tecnologías de la información.

A la luz de estos objetivos finales, comprobamos que el aprendizaje propuesto se centra en contenidos que posteriormente responden a destrezas desarrolladas mediante al análisis, cotejo, interpretación y valoración o interpretación personal. Destaca la capacidad crítica que debe mostrar el alumno a partir de la lectura de fragmentos u obras completas, en consonancia con el nivel de madurez cognitiva que ha debido formarse en los anteriores estadios educativos; se entiende, por tanto, la necesidad de aplicar un método de reflexión poética procedimental y actitudinal que asiente las bases para adquirir las nuevas competencias.

En cuanto a dichas competencias, en la Orden ECD/65/20I5, de 2 I de enero, por la que se describen las relaciones entre las competencias ${ }^{3}$, los contenidos y los criterios de evaluación de la educación primaria, la educación secundaria obligatoria y el

\footnotetext{
${ }^{3}$ En el artículo 2 se recogen las siete competencias clave: Comunicación lingüística, Competencia matemática y competencias básicas en ciencia y tecnología, Competencia digital, Aprender a aprender, Competencias sociales y cívicas, Sentido de iniciativa y espíritu emprendedor, y Conciencia y expresiones culturales.
} 
bachillerato (BOE, 25, de 29 de enero de 20I5), el Anexo I desarrolla las competencias en el título "Descripción de las competencias clave del Sistema Educativo Español”. La competencia en comunicación lingüística se describe como potenciadora de actitudes y valores del individuo, del respeto a las normas de convivencia, del ejercicio de la ciudadanía, del espíritu crítico y del respeto a los derechos humanos. Asimismo, es propiciadora del diálogo como herramienta primordial para la convivencia, la resolución de conflictos y el desarrollo de las capacidades afectivas en todos los ámbitos. Las destrezas inherentes a esta competencia (lectura, conversación, escritura, etc.) fomentan el disfrute personal y motivan el aprendizaje. Los mencionados objetivos, tan importantes en la legislación educativa, no hacen sino corroborar el valor competencial de la literatura desde su triple dimensión. Por tanto, los objetivos y las capacidades se interrelacionan en el desarrollo de destrezas comunicativas orales y escritas, de expresión y de comunicación, del tratamiento especial de los valores (Campos F.-Fígares y García Rivera, 2OI7), del fomento de la alfabetización artística, del conocimiento del lenguaje poético, y del sentimiento de grupo e interacción social, entre otros.

\section{Manuales y educación poética}

Con el fin de analizar el enfoque que los manuales de segundo de Bachillerato aplican a la práctica poética en relación con el periodo literario más próximo a la actualidad, procedemos a realizar una investigación mediante la metodología de análisis cualitativo comparado de los conceptos curriculares y los instrumentos de análisis empleados en los mismos. El estudio cualitativo de los resultados nos permite valorar cómo se concretan los principios que recoge la legislación educativa y qué métodos se emplean en la praxis docente.

Para abordar este trabajo, analizamos cuatro manuales ${ }^{4}$ empleados en las aulas de forma habitual (desde nuestra experiencia): Inicia Duat ${ }^{\text {, Proyecto Saber Hacer }}{ }^{6}$, Proyecto Savia ${ }^{7}$ y 2 Bachillerato Teide ${ }^{8}$. En general, comprobamos que el método para el conocimiento poético desde la práctica se realiza en estos libros mediante las cuestiones incluidas en el comentario o análisis de texto, por tanto, es el único instrumento procedimental. Mostramos una plantilla para cada manual en la que consignamos los siguientes ítems: tema en el que se incluye la poesía actual, número de páginas que ocupa, poemas tienen comentario de texto, objetivos curriculares (criterios de aprendizaje) y guía de comentario final.

\footnotetext{
${ }^{4}$ Quede constancia expresa de que no es nuestra intención valorar ninguna editorial puesto que entendemos que todas cumplen con los criterios de calidad requeridos para su publicacion.

5 Lobato Morchón, R. y Lahera Forteza, A. Lengua Castellana y Literatura 2 Bachillerato. Inicia Dual. Madrid: Oxford University Press, 2016.

${ }^{6}$ Grence Ruiz, Teresa (dir.). Lengua y Literatura 2 Bachillerato. Serie Comenta. Proyecto Saber Hacer. Madrid: Santillana, 2016.

7 Blecua, J. M. (coord.). Lengua Castellana y Literatura 2 Bachillerato. Proyecto Savia. Madrid: SM, 2016.

${ }^{8}$ Fortuny, J., Martí, S., López, M. y Ráfols, J. Lengua castellana y Literatura 2 Bachillerato. Proyecto Savia. Barcelona: Teide, 2016.
} 
I. INICA DUAL

\begin{tabular}{|l|l|}
\hline Proyecto editorial & Inicia Dual \\
\hline Tema & La lírica posterior a 1936 \\
\hline Páginas & $216-235$ (20 páginas) \\
\hline Corpus poético para comentar & 19 poemas \\
\hline Objetivos curriculares & $\begin{array}{l}\text { 1. Identificar temas o alusiones temáticas. } \\
\text { 2.*Analizar } \text { o identificar recursos estilísticos. } \\
\text { 3. Reconocer rasgos de un poeta. } \\
\text { 4. Analizar métrica o estructura. } \\
\text { 5. *Identificar época, corriente o rasgos del período. } \\
\text { 6. Responder a preguntas específicas: emisor, recep- } \\
\text { tor, connotación léxica, emociones, etc. } \\
\text { 7. Redactar interpretación. } \\
\text { 8. Redactar texto con características poéticas y ejem- } \\
\text { plificar con el poema. } \\
\text { 9. Buscar información en internet o enciclopedia } \\
\text { para referencias destacadas. }\end{array}$ \\
\hline Guía comentario & $\begin{array}{l}\text { Guía para un comentario de un poema con la estruc- } \\
\text { tura siguiente: análisis del contenido, análisis formal } \\
\text { y contextualización (diez preguntas). }\end{array}$ \\
\hline Otros & $\begin{array}{l}\text { Se recomienda la audición de algunos poemas (el } \\
\text { libro incluye el acceso a recursos digitales) antes de } \\
\text { proceder a su comentario. }\end{array}$ \\
\hline
\end{tabular}

El instrumento curricular para la práctica poética es el comentario de texto. Diecinueve poemas se abordan a partir de la estrategia "Análisis de textos", que formula una media de tres preguntas para cada uno. Predominan las cuestiones de carácter conceptual (identificación o reconocimiento, redacción y búsqueda de información) frente a las que incluyen contenidos procedimentales y actitudinales (análisis, preguntas específicas de connotación y redacción de textos interpretativos). El final del tema muestra una "Guía para el comentario" desplegada en diez preguntas que se dividen en los bloques: análisis del contenido, análisis formal y contextualización (se emplea de forma general esta estructura para analizar los diferentes géneros literarios propuestos en el temario).

9 Destacamos con un asterisco los objetivos más empleados (por lo general, estos duplican el uso de los restantes) en dichos manuales. 


\section{PROYECTO SABER HACER}

\begin{tabular}{|c|c|}
\hline Proyecto editorial & Proyecto Saber Hacer \\
\hline Tema & La poesía desde 1975 \\
\hline Páginas & 334-349 (16 páginas) \\
\hline Corpus poético para comentar & 11 poemas \\
\hline Objetivos curriculares & $\begin{array}{l}\text { 1. Relacionar poesía y su fuente, o tema con corrie- } \\
\text { nes. } \\
\text { 2. *Justificar rasgos de un período, un texto que trata } \\
\text { un tema. } \\
\text { 3. *Explicar actitud y sentimientos, emociones, to- } \\
\text { nos, situaciones vitales. } \\
\text { 4. *Comparar dos poemas: corrientes, relaciones o } \\
\text { interés. } \\
\text { 5. Trabajar la interdiscursividad: música-poesía (te- } \\
\text { mas, recursos o semejanzas). } \\
\text { 6. *Responder preguntas dirigidas: connotaciones, } \\
\text { tema, título, alusiones culturales, mitos, tópicos lite- } \\
\text { rarios, mundos, casos de metapoesía o yo poético. } \\
\text { 7. Buscar información: vida y obra de poetas. }\end{array}$ \\
\hline Guía comentario & $\begin{array}{l}\text { "Claves para el comentario de... un poema actual", } \\
\text { que organiza en diecisiete preguntas los siguientes } \\
\text { apartados: identificar el tema, comentar la métrica } \\
\text { y el ritmo, analizar el lenguaje y contextualizar el } \\
\text { poema. }\end{array}$ \\
\hline
\end{tabular}

El instrumento curricular para el desarrollo de la práctica poética es el comentario de texto. Cada poema se analiza mediante preguntas, una media de cuatro (valórese que el periodo es menos amplio que el del manual anterior). Ofrece un adecuado predominio de cuestiones que valoran la capacidad crítica e interpretativa que se le exige al alumno de este nivel curricular; en este sentido, se incluyen preguntas de cotejo, justificación, análisis, valoración, etc., en suma, se fomenta la visión personal y la interconexión de saberes. Asimismo, se incluye una perspectiva muy adecuada -y poco empleada en Bachillerato- que es la interdiscursividad; de forma concreta, las relaciones que se establecen entre la música (lenguaje propio de la adolescencia) y la poesía. La pregunta de carácter conceptual responde a las técnicas de indagación o búsqueda de información de la vida y la obra de los poetas. Las claves para el comentario se completan con una guía de análisis con diecisiete cuestiones en torno a estos apartados: identificar el tema, comentar la métrica y el ritmo, analizar el lenguaje y contextualizar el poema. 


\section{PROYECTO SAVIA}

\begin{tabular}{|l|l|}
\hline Proyecto editorial & Proyecto Savia \\
\hline Tema & La poesía desde los años sesenta \\
\hline Páginas & $348-367$ (20 páginas) \\
\hline Corpus poético para comentar & 21 poemas \\
\hline Objetivos curriculares & $\begin{array}{l}\text { 1. Identificar temas. } \\
\text { 2. Identificar estructura o rasgos lingüísticos. } \\
\text { 3. Desarrollar temas: diferencias entre poetas, in- } \\
\text { fluencias. } \\
\text { 4. *Responder preguntas dirigidas: yo poético, regis- } \\
\text { tro lingüístico o sensualidad. } \\
5 . * \text { Explicar actitud y sentimientos, emociones, tonos } \\
\text { o situaciones vitales. } \\
\text { 6. *Justificar o vincular rasgos de un período, o de la } \\
\text { poética del autor. } \\
\text { 7. Redactar valoración crítica. } \\
\text { 8. Comentar relaciones interdiscursivas: pintura y } \\
\text { cine. }\end{array}$ \\
\hline Guía comentario & $\begin{array}{l}\text { “Guía de lectura" de un poemario concreto. Pro- } \\
\text { puestas del comentario de dos poesías (cada una } \\
\text { incluye ocho preguntas) a partir del siguiente es- } \\
\text { quema: comentario lingüístico, comentario crítico y } \\
\text { desarrollo de temas. }\end{array}$ \\
\hline
\end{tabular}

El comentario de texto es la estrategia empleada para el análisis poético. Se incluyen veintiún poemas con sus correspondientes preguntas entre las que se aprecia un predominio de contenidos procedimentales y actitudinales: explicación o justificación, valoración crítica, comentario de relaciones interdiscursivas, establecimiento de diferencias, etc.; en suma, destaca el trabajo de análisis e interpretación. Algunas cuestiones de carácter conceptual responden a la identificación de temas o rasgos. El esquema para el comentario final de los dos poemas propuestos se estructura en cuestiones lingüísticas, comentario crítico y desarrollo de temas. 
4. 2 BACHILLERATO TEIDE

\begin{tabular}{|c|c|}
\hline Proyecto editorial & 2 Bachillerato Teide \\
\hline Tema & $\begin{array}{l}\text { La literatura desde la década de } 1960 \text { hasta la actua- } \\
\text { lidad } \\
\text { La lírica }\end{array}$ \\
\hline Páginas & 307-311, 321 (6 páginas) \\
\hline Corpus poético para comentar & 5 poemas \\
\hline Objetivos curriculares & $\begin{array}{l}\text { 1. Resumir poema. } \\
\text { 2. Identificar recursos estilísticos concretos (metáfo- } \\
\text { ras y connotaciones, imágenes, etc.). } \\
\text { 3. Responder a cuestiones precisas: tema, yo poético } \\
\text { o connotaciones léxicas. } \\
\text { 4. *Explicar sentimientos, emociones, tonos o situa- } \\
\text { ciones vitales. } \\
\text { 5. *Justificar o vincular rasgos (temáticos, estilísti- } \\
\text { cos...) de un período o de la poética del autor. }\end{array}$ \\
\hline Guía comentario & $\begin{array}{l}\text { Comentario que incluye diez preguntas estructuradas } \\
\text { en los siguientes apartados: localización, análisis del } \\
\text { contenido y de la expresión, y valoración y creación. }\end{array}$ \\
\hline
\end{tabular}

El comentario de texto es el instrumento curricular empleado para la práctica poética. Cuatro poemas se comentan en perspectiva comparada a partir de preguntas sobre el tono, los temas, las sensaciones o los sentimientos, las connotaciones y los rasgos estilísticos. El poema restante recoge cinco cuestiones similares a las anteriores. Se valora la capacidad de relacionar conceptos y se solicita, asimismo, el resumen de cada poema. El análisis se complementa con la propuesta de un comentario final a partir de diez preguntas que se estructuran en tres apartados: localización, análisis del contenido y de la expresión, y valoración y creación (este es muy adecuado puesto que fomenta la creación literaria a partir de la escritura de un poema minimalista).

A la luz del cotejo de los manuales comprobamos que el instrumento curricular para la práctica poética es el comentario de texto. Los libros de texto aplican los elementos curriculares de la legislación educativa en sus tres dimensiones competenciales. En cuanto a los contenidos conceptuales, estos plantean la redacción de textos de características de la época estudiada, el resumen de contenido, la identificación de temas, el reconocimiento de rasgos y la búsqueda de información de vida y obras de autores. De forma general, se desarrollan los contenidos procedimentales y actitudinales en consonancia con los estándares propuestos por la normativa educativa (analizar, comparar, interpre- 
tar de manera crítica, aportar una visión personal, etc.). Destaca en estos manuales, por tanto, la interpretación que se exige al alumno en consonancia con su formación y nivel madurativos. Al margen de este cotejo legislativo y teniendo en cuenta los principios destacados, valoramos la adecuación de haber practicado en estadios educativos anteriores un método de reflexión poética procedimental.

\section{Un modelo de poesía para el comentario: Umbrales de otoño, de Mariluz Escri- bano}

En los últimos años se está realizando un trabajo de recuperación literaria, en concreto, de la poesía escrita por mujeres (Rosal Nadales, 2006 o Lanseros y Merino, 20I6, entre otros estudios), que se complementa con investigaciones teóricas (Sánchez García, 20I5, 20I7 y 20I8) que reivindican la necesaria incorporación de estas voces al canon, voces de poetas silenciadas por su condición de mujer (Sánchez García, 2OI9). Es necesario recuperar este canon sumergido para darle su merecido protagonismo en el aula y, en este sentido, destacamos la magnífica y amplia creación de la autora granadina Mariluz Escribano. Entre sus numerosos reconocimientos literarios, mencionamos el galardón “Autora Andaluza Clásica del Año," concedido por el Centro Andaluz de las Letras en el año 2O2I. Como se ha indicado, reivindicamos, desde la perspectiva curricular, la incorporación de estas autoras en los manuales, programas o proyectos educativos, son escritoras que han sido injustamente oscurecidas y cuya calidad literaria es reconocida. Es el aula, por lo tanto, un lugar idóneo para visibilizar estas autoras y completar, de esta forma, los elementos curriculares de la enseñanza.

La profesora Remedios Sánchez está realizando una encomiable labor de recuperación y reconocimiento de la figura y producción de Mariluz Escribano (2OI9, 202O coord.). Su elenco creador es amplio e invitamos a la lectura de sus obras en las aulas (ensayo, poesía, relatos, etc.). Con el fin de mostrar algunos aspectos que guían el comentario de texto, hemos seleccionado el poema titulado "Septiembre", que pertenece a la primera parte de Umbrales de otoño (2OI3: 4I):

Septiembre y amanece

con la amarilla luz de los veranos,

con un rastro lejano de tranvías

circulando por calles y por plazas,

jardines de pobreza

de una ciudad con nombre de granada,

y pálidos viajeros,

de norte a sur cruzando

aquel sol de la infancia, 
aquel día de luz

escapado de un atlas.

Septiembre y anochece,

los niños, deslumbrados,

sueñan con adjetivos.

Procedemos a mostrar las fases que consideramos necesarias (es una guía con la correspondiente flexibilidad a la que invita cada lectura) para analizar un poema en segundo curso de Bachillerato. Entendemos que las cuestiones teóricas se han impartido como procede para cualquier tema, sin entrar en valoraciones sobre la metodología aplicada. En primer lugar, partimos de la importancia de realizar una aproximación lectora conjunta que puede programarse, en primer lugar, como lectura silenciosa (se recomienda tomar notas) y, posteriormente, como recitación compartida (bien por el profesor, bien por el alumno). Este espacio poético común permite comentar y compartir sensaciones, sentimientos, emociones, etc.; en suma, constituye una invitación para aproximarse al tema de forma sugerente. Tras este primer encuentro, mostramos las cinco fases -no deben tomarse como compartimentos estancos- propuestas como un trayecto al que invita cada poema: r. Comentario del tema: tono, connotaciones, relaciones e impresiones; 2. Versificación vinculada al contenido; 3. Análisis lingüístico-retórico o estilístico; 4 . Contextualización justificada en la producción y en la corriente poética; y 5. Valoración: interpretación personal crítica.

\section{Comentario del tema: tono, connotaciones, relaciones e impresiones.}

El título "Septiembre" es el mes en que fue fusilado su progenitor, tiempo de transición de estaciones que marca, asimismo, la mudanza del estado anímico (ahora es angustia) de la autora.

El elemento temático clave lo constituye la indagación continua en la infancia, en una niñez que ha dejado honda huella causada por la pérdida de su padre. El paso del tiempo y el tono nostálgico muestran, entre otras, claras influencias machadianas y juanramonianas.

El poema se desarrolla en un granadino día de septiembre (desde el amanecer al anochecer). La estructura bipartita ofrece un juego retórico merced al uso de versos heptasílabos de estructura paralela bimembre con contraste semántico: Septiembre y amanece (v.I), y Septiembre y anoche (v. I2). Así, la primera parte (vv. I-IO) se halla formada por la enumeración de objetos y lugares de "una ciudad con nombre de granada" por la que caminan viajeros vinculados con sensaciones principalmente cromáticas (amarilla luz, pálidos viajeros, sol de la infancia, día de luz), adultos que transitan por un "sol de la infancia” o por una luz que va declinando en el anochecer (la segunda parte abarca los versos I2 a I4) mientras los niños -“deslumbrados” o confusos- tienen esperanzas o ilusiones. 


\section{Versificación vinculada al contenido.}

El estudio de la métrica debe realizarse a partir de una lectura integradora y comprensiva en la que se muestra la relación entre contenido y versificación. El cuidadoso estilo de la composición es un testimonio más de su estudiada construcción, caracterizada por el minucioso arte de la medida conjugado con la libertad que singulariza a la autora. Los versos que la componen constituyen una ruptura con las formas métricas tradicionales, no es una lira si bien es un guiño a la métrica tradicional (a los autores clásicos que tan bien conoció). La forman tiradas de diez versos blancos heptasílabos y cuatro endecasílabos estratégicamente ubicados a partir del segundo verso con el objetivo de ampliar la descripción del contraste entre el agradable fondo que dibuja la amarilla luz de los veranos y los tranvías que circulan por las calles de Granada; estos versos endecasílabos ralentizan el ritmo del poema, contribuyen a que la descripción se desarrolle en un continuum rítmico que contrasta con la rapidez enumerativa de los heptasílabos, esencia que culmina en el cambio de luz porque anochece con versos de siete sílabas. La estructura interna del poema, que responde a la mudanza de luz (asociada a vida y sentimientos) se justifica, asimismo, desde el magistral dominio de la métrica de Escribano.

\section{Análisis lingüístico-retórico o estilistico.}

El objetivo de este apartado es valorar el uso específico de recursos estilísticos, tropos, símbolos, juegos o usos lingüísticos, etc., propios de la lengua literaria. A modo de ejemplo, esbozamos el contraste simbólico de la luz del amanecer frente a la luz del anochecer; la luz crepuscular de la tarde al borde de la noche constituye un momento mágico (recurrente en la poética de Mariluz, y en Lorca, por ejemplo) en el que se siente la transición de la luz a la oscuridad, que simboliza el retorno (noche como fin o muerte). La noche es símbolo del origen y también del dramático destino del ser humano, y evoca la oscuridad temporal de raíces ancestrales; es el principio de la alternancia de los contrarios o de la armonía de los opuestos (Cirlot, 1992).

Se pueden comentar otros aspectos, algunos de los cuales dejamos bosquejados: los paralelismos aportan la sensación de la reiteración vana de lo cotidiano (con la amarilla luz de los veranos, / con un rastro lejano de tranvías (vv. 2-3); la tautología (ciudad con nombre de granada) es un juego retórico de reminiscencias infantiles; el empleo de la personificación (aquel día de luz/escapado de un atlas, wv. 9-IO) es una vinculación con el pasado; la sensación de movimiento "mecánico" de las acciones cotidianas (circulando, cruzando...) frente al estatismo; el valor del sueño de una infancia que fue paraíso perdido; el tono melancólico del recuerdo entreverado en la creación de un ambiente crepuscular transido por el contraste realidad cotidiana / sueño o recuerdo infantil; el continuo uso del presente que conduce, asimismo, al pasado porque la memoria de la infancia es el puente que une el paso del tiempo; o las coordenadas temporales (septiembre, verano) que responden a un cronotopo de tintes trágicos, entre otras cuestiones. 


\section{Contextualización justificada en la producción y en la corriente poética.}

Constituye el quinto poema de la primera parte de Umbrales de otoño, obra dividida en dos secciones: la primera -sin título- está compuesta por diecisiete poesías escritas en verso libre. En palabras de Sánchez García (2OI3: 2O-2I), es "una summa de los asuntos que habitualmente preocupan a Escribano, [...] tomando siempre como brújula guía la memoria, [...] para facilitar la incorporación del lector al propio universo poético". La segunda parte, "Humo remansado", la conforman dieciocho poemas que reviven un discreto amor. El conjunto que compone la primera parte recoge temas en torno a la figura de los padres, a la amistad y a la infancia, y lo hace desde la mirada evocadora que reconstruye con desasosiego, pero sin odio.

La autora no se adscribe a ninguna corriente poética; sus lecturas e influencias se aprecian en toda su producción y son, según se ha indicado, Antonio Machado, Juan Ramón Jiménez, Miguel Hernández, escritores del 27 y, en general, poetas españoles clásicos y del siglo XX. Se puede valorar el análisis de alguna concomitancia con coetáneas, por ejemplo, con Paca Aguirre en su incansable búsqueda por reconstruir la memoria junto con la pérdida paterna.

\section{Valoración: interpretación personal crítica.}

Esta escritora había iniciado su trayectoria, que no dio a conocer con anterioridad, incluso había destruido parte de su producción, y empezó a desarrollar su faceta como escritora en I957 aunque no publica hasta 199I. Es autora de una obra poliédrica que evidencia su carácter inclasificable dentro de una corriente específica, así su técnica se ciñe a una preciosista y aquilatada construcción, emplea una cuidada métrica y su estilo descubre los recovecos más intimistas que afloran en sus sentimientos. Sus circunstancias vitales son materia de creación y su poesía es, por tanto, testimonio de vida (Martínez Ezquerro, 2O2O). Muestra una indagación continua en la infancia, en una niñez que dejó honda huella y que se concreta en la vivencia de la pérdida del padre.

Su poesía se forja desde la búsqueda por reconstruir la memoria, y se halla transida por el desasosiego y el deseo de comunicación en un simbólico marco que huye de lo urbano para situarse en una naturaleza henchida de elementos que imprimen voz propia a su creación literaria (al más puro estilo lorquiano). Su visión intimista se aprecia en la mirada nostálgica desde un presente en soledad que acrecienta la angustia por la falta de comunicación y que se vincula a un pasado también solitario por la pérdida de la figura paterna. En suma, poesía en clave personal que busca la recuperación de la memoria y que se despliega con absoluta riqueza de matices. 


\section{Conclusiones}

La poesía, basada en el fomento de las competencias curriculares, desempeña un papel educativo fundamental; pero este género, después del teatro, es uno de los olvidados en las aulas y, de forma significativa, en Educación Secundaria. A la luz de estas carencias, hemos mostrado un método de análisis textual comprensivo adecuado al nivel, currículo y diversidad del alumnado adolescente.

Con el fin de comprobar la realidad del contexto educativo, hemos analizado el enfoque legislativo para la educación poética y concluimos que es teóricamente adecuado puesto que incluye la triple dimensión competencial. Asimismo, hemos comprobado estos principios en los manuales cotejados, estudio que permite determinar que se practica este género a partir del comentario o análisis textual de forma generalizada (con la inclusión de contenidos no solo conceptuales sino también procedimentales y actitudinales) pero no plantea la intervención curricular como reflexión, experiencia y espacio compartido.

Teniendo en cuenta las necesidades que arroja el estudio comparativo, desarrollamos la "metodología de reflexión poética activa" como un instrumento de intervención literaria guiado por el docente -educador de la sensibilidad literaria- en un espacio colaborativo de reflexión compartida en el que se fomenta la capacidad crítica (imprescindible en este nivel educativo, Sánchez García, F. J., 202I); que, además, tiene en consideración la diversidad del alumnado para adecuar el corpus lector. Esta metodología es una útil propuesta que otorga protagonismo al desarrollo competencial en su triple dimensión, esto es, conceptual, procedimental y actitudinal, en consonancia con los principios de la legislación educativa.

La ejemplificación del método propuesto se realiza a partir del poema "Septiembre”, de la insigne escritora granadina Mariluz Escribano; este análisis ha permitido, por un lado, destacar su figura como representante de muchas voces femeninas silenciadas en los manuales de Secundaria; y, por otro lado, mostrar las fases del comentario como una guía flexible a la que invita cada texto, cada lectura, cada trayecto. En suma, la educación poética debe abordarse con un enfoque metodológico que fomente, principalmente, la capacidad interpretativa inherente al análisis literario y en un espacio de reflexión compartida. 


\section{Referencias bibliográficas}

- Barrientos, C. (I999). Claves para una didáctica de la poesía. Textos de didáctica de la lengua y la literatura, 2I, I7-34.

- Blecua, J. M. (coord.) (20I6). Lengua Castellana y Literatura 2 Bachillerato. Proyecto Savia. Madrid: SM.

- Campos F.-Fígares, M. (20i6). Clubes de lectura e interculturalidad. En Martínez Ezquerro, A. y Campos Fernández-Fígares, M. (eds.). Cultura en la diversidad: educación lingüística y literaria en las aulas del siglo XXI. Barcelona: Octaedro, I53-I65.

- Campos F.-Fígares, M. y García Rivera, G. (2OI7). Aproximación a la ecocrítica y la ecolectura: literatura juvenil e imaginarios del agua. Ocnos: Revista de Estudios sobre Lectura, i6 (2), 95-IO6. DOI: https://doi.org/IO.I8239/ocnos_2OI7.I6.2.I5II

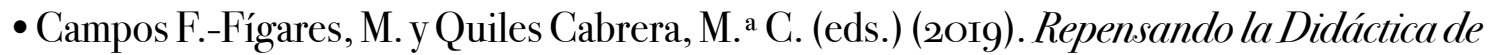
La lengua y la Literatura. Líneas emergentes de investigación. Madrid: Visor Libros.

- Cirlot, J. (r992). Diccionario de símbolos. Barcelona: Labor, 2. ${ }^{\text {a }}$ ed.

- Escribano Pueo, M. (2013). Umbrales de otoño. Estudio preliminar de R. Sánchez García. Madrid: Hiperión.

- Fortuny, J., Martí, S., López, M. y Ráfols, J. (20I6). Lengua castellana y Literatura 2 Bachillerato. Proyecto Savia. Barcelona: Teide.

- García Montero, L. (I999). Lecciones de poesía para niños inquietos. Granada: Comares.

- García Rivera, G. (I995). Didáctica de la literatura para la enseñanza primaria y secundaria. Madrid: Akal.

- Gómez Martín, F. (2002). Didáctica de la poesía en la Educación Secundaria. Madrid: Secretaría General Técnica, Subdirección Gral. de Información y Publicaciones, MEC.

- Grence Ruiz, T. (dir.) (20I6). Lengua y Literatura 2 Bachillerato. Serie Comenta. Proyecto Saber Hacer. Madrid: Santillana.

- Lanseros, R. y Merino, A. (20i6). Poesía soy yo. Madrid: Visor.

- Leal Rivas, N. (2020). La competencia lecto-crítica en entornos digitales: una visión holística para L2/LE. Contextos Educativos, 25, 7 I-89. DOI: https://doi.org/IO.I8I72/con. 4267 
- Lobato Morchón, R. y Lahera Forteza, A. (20I6). Lengua Castellana y Literatura 2 BachiIlerato. Inicia Dual. Madrid: Oxford University Press.

- Lomas, C. (I999). La educación poética. Textos de didáctica de la lengua y la literatura, 2I, $5^{-\mathrm{I} 6}$.

- López Valero, A. y Encabo, E. (2013). Fundamentos didácticos de la lengua y la literatura. Madrid: Editorial Síntesis.

- López Valero, A. y Jerez, I. (20IO). Lectura. escritura y democracia de la cultura. experiencias con la creación literaria. Alabe, 2, I-I6. DOI: http://dx.doi.org/IO.I5645/Alabe.2OIO.2.2

- Martínez Ezquerro, A. (2002). Didáctica de las figuras retóricas. Actividades para el aprendizaje creativo de las figuras fonológicas. Barcelona: Ediciones Octaedro.

- Martínez Ezquerro, A. (20I6). El método de cooperación interpretativa como estrategia lectora. Alabe, I4, I-2O. DOI: http://dx.doi.org/ı.I5645/Alabe2OI6.I4.I

- Martínez Ezquerro, A (20I7). De la retórica y poética a la literatura: contexto educativo, disciplinas y manuales en el siglo XIX. Dicenda. Cuadernos de Filología Hispánica, 35, I85$2 \mathrm{O} 3$.

- Martínez Ezquerro, A. (2O2O). Los versos son mi vida. A Mariluz Escribano, in memoriam. EntreRíos. Revista de Arte y Letras. Monográfico "Mariluz Escribano, El corazón de la gacela”, 29-30, I8I-I87.

- Martínez Ezquerro, A., Pérez Pastor, J. L. y Beltrán Falces, C. (2008). Música de las esferas. Literatura en el aula. Logroño: Ediciones del 4 de agosto.

- Martínez Ezquerro, A. y Quiles Cabrera, M. ${ }^{a}$ C. (2Or9). Poesía visual y vídeo-poesía. En Poesía en red y ciberpoesía. Campos Fernández-Fígares. M. y Escandell Montiel. M. (eds.). Revista Caracteres. Disponible en: http://revistacaracteres.net/poesia-en-red-y-ciberpoesia. Alicante: Fundación Cultural Miguel Hernández, 32-40.

- Martos, E. y Campos, M. (2OI2). La lectura y la escritura en el s. XXI: Cultura letrada y modernidad. Alabe, 5, I-I2. DOI: http://dx.doi.org/IO.I5645/Alabe.2OI2.5.I3

- Moreno. V. (1989). Eljuego poético en la escuela. Pamplona: Pamiela.

- Moreno, V. (I999). Textos poéticos en la educación secundaria. Textos de didáctica de la lengua y la literatura, 2I, 35-48. 
- Muñoz, M. (1983). La poesía y el cuento en la escuela. Madrid: Consejería de Educación y Juventud de la Comunidad de Madrid.

- Ortega, E. (I986). El baúl volador. Un taller de Literatura en el Bachillerato. Zamora: Consejería de Educación y Cultura. Junta de Castilla y León.

- Pardo Caicedo, M. y Munita, F. (202I). Resignificar la poesía en las aulas de secundaria: la visión sobre educación poética de tres profesores de referencia en España. Revista Complutense de Educación, $3^{2}$ (2), I95-204. https://doi.org/IO.5209/rced.6829

- Quiles Cabrera, M. ${ }^{a}$ C. (2O2O). Textos poéticos y jóvenes lectores en la era de internet: de booktubers, bookstagrammers y followers. Contextos Educativos, 25, 9-24. DOI: http:// doi.org/IO.I8I72/con.4260

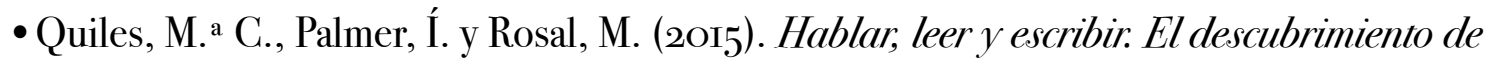
las palabras y la educación lingüística y literaria. Madrid: Visor Libros.

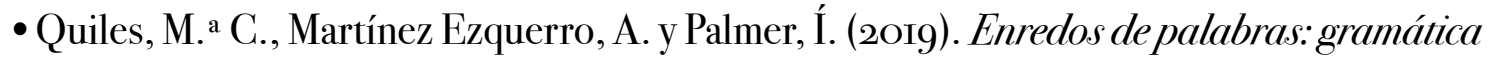
y uso de la lengua en nuevos espacios de comunicación. Barcelona: Graó.

• Rincón, F. y Sánchez-Enciso, J. (I986). El alfar de poesía. Barcelona: Teide.

- Rodari, G. (1983). La gramática de la fantasía. Barcelona: Avance.

- Rosal Nadales, M. (2006). Con voz propia. Antología comentada de la poesía escrita por mujeres. Sevilla: Renacimiento.

- Sánchez García, F. J. (202I). Educar la mirada. El discurso informativo de las fake news en el currículo de Secundaria y Bachillerato. Contextos Educativos, 27, I53-I57. DOI: https:// doi.org/IO.I8I72/con.4865

- Sánchez García, R. (20I5). El canon abierto. Última poesía en español (1970-1985). Madrid: Visor Libros.

- Sánchez García, R. (2018). Así que pasen treinta años... Historia interna de la poesía española contemporánea (1950-2OI7). Madrid: Ediciones Akal.

- Sánchez García, R. (2019). Canon escolar poético y pedagogía literaria en bachillerato. Las escritoras invisibles en los manuales de literatura. Pedagogía Social. Revista interuniversitaria, $33,43-52$.

- Sánchez García, R. (2020). Mariluz Escribano, historia de una Maestra (cuando la ausencia es un dolor y una bandera). Álabe 2I. [www.revistaalabe.com] DOI: IO.I5645/Alabe2O2O.2I.I3 
- Sánchez García, R. (coord.) (2O2O). Mariluz Escribano, El corazón de la gacela. Entre Ríos. Revista de Arte y Letras.

- Sánchez García, R. y Gahete, M. (coords.) (20I7). La Palabra Silenciada. Voces de Mujer en la Poesía Española Contemporánea (1950-20I5). Valencia: Tirant Humanidades.

- Sánchez García, R, y Aparicio Durán, P. (2020). Los hijos de Instagram. Marketing editorial. Poesía y construcción de nuevos lectores en la era digital. Contextos Educativos, 25, 4I-53. DOI: https://doi.org/IO.I8I72/con.4265

- Sánchez-Enciso, J. (2004). Leer, interpretar y hacer poesía. Textos de didáctica de la lengua y la literatura, $35,46-5^{8}$.

- Sánchez-Enciso, J. y Rincón, F. (1985). Los talleres literarios (una alternativa didáctica al historicismo). Montesinos: Barcelona.

- Spang, K. (1997). Fundamentos de retórica. Pamplona: Eunsa.

- Spang, K. (2005). Persuasión. Fundamentos de retórica. Pamplona: Eunsa.

\section{Referencias legislativas}

- LEY ORGÁNICA 8/2OI3, de 9 de diciembre, para la mejora de la calidad educativa (BOE, Io de diciembre de 20I3).

- Real Decreto iто5/20I4, de 26 de diciembre, por el que se establece el currículo básico de la Educación Secundaria Obligatoria y del Bachillerato (BOE, 3 de enero de 2OI5).

- Orden ECD/65/2OI5, de 2I de enero, por la que se describen las relaciones entre las competencias, los contenidos y los criterios de evaluación de la Educación Primaria, la Educación Secundaria Obligatoria y el Bachillerato. BOE, de 29 de enero de 2OI5). 